\title{
As Estratégias da Saúde da Família no enfrentamento das violências envolvendo adolescentes
}

\author{
Family Health Strategies to tackle violence involving adolescents
}

Moysés Francisco Vieira Netto ${ }^{1}$

Suely Ferreira Deslandes ${ }^{1}$

${ }^{1}$ Instituto Fernandes Figueira, Fiocruz. Av. Rui Barbosa 716, Flamengo. 22250-020 Rio de Janeiro RJ Brasil.

mfvnetto@hotmail.com
Abstract The Family Health Strategy (FHS) has an acknowledged potential for the promotion of health and the prevention of violence. This is an integrative bibliographic review with the aim of evaluating the performance of FHS professionals in tackling and preventing violence involving adolescents. It is an integrative review of dissertations and theses on healthcare published from 1994 to 2014. The collection of 17 dissertations and $2 \mathrm{doc}$ toral theses reveals that these studies are recent. The FHS professionals acknowledge the vulnerability of adolescents to inflicting and being subject to violence, however the FHS proves ineffective in tackling and preventing such violence. The predominance of the medical technical care model, the deficiencies in Public Health education in professional training and the lack of institutional support are seen as the main obstacles. Many of these professionals are unaware of the files for notification of violence. The existence of family violence and criminal groups were the aspects most mentioned in the territories. The social representation of adolescents as being "problematic" and the lack of ESF actions that promote an increase youth leadership and empowerment were clearly detected.

Key words Violence, Adolescent, Family Health Strategy
Resumo A Estratégia Saúde da Família (ESF) apresenta reconhecido potencial para a promoção da saúde e a prevenção das violências. Trata-se de revisão bibliográfica integrativa com o objetivo de avaliar a atuação dos profissionais da ESF no enfrentamento e prevenção das violências envolvendo adolescentes. O acervo foi de 17 dissertações e 2 teses da área da saúde, entre 1994 e 2014, e evidencia que são recentes os estudos sobre o tema. Os profissionais reconhecem a vulnerabilidade do adolescente para praticar e sofrer violências, entretanto a ESF mostra-se pouco atuante no enfrentamento e prevenção das mesmas. O predominio do modelo médico técnico assistencial, as deficiências do ensino de Saúde Coletiva na formação dos profissionais e a falta de respaldo institucional são apontados como entraves. Muitos desses profissionais desconhecem a ficha de notificação das violências. A violência familiar e a de grupos criminosos foram as mais citadas como presentes nos territórios. Verifica-se a reprodução da representação social do adolescente como "problemático" e a ausência de ações da ESF que promovam o protagonismo juvenil e o seu empoderamento. Palavras-chave Violência, Adolescente, Estratégia Saúde da Família 


\section{Introdução}

A violência tem sido um dos grandes desafios para as agências públicas e os sistemas de saúde ${ }^{1}$. A Organização Mundial (OMS) e a Organização Pan Americana de Saúde (OPAS), a partir da década de 1990, reconhecem oficialmente as violências como o maior e mais crescente problema de saúde pública no mundo ${ }^{1}$. Todavia, a apropriação do tema da violência e sua legitimação pela Saúde como objeto de pesquisa, intervenção e formulação de políticas é relativamente recente no Brasil ${ }^{2,3}$.

Tomando-se o conceito de vulnerabilidade enquanto um constructo que delimita, nos planos individual, biológico, sociocultural, programático e institucional, os diferentes capitais disponíveis e capazes de proteger pessoas e coletividades dos agravos à saúde ${ }^{4}$, podemos afirmar que os adolescentes são um dos grupos mais vulneráveis da nossa sociedade para sofrerem violências ${ }^{5}$.

Constata-se que no Brasil a violência constitui há mais de duas décadas a principal causa de morte entre adolescentes ${ }^{5}$. Segundo o mais recente mapeamento da violência juvenil no Brasil, os adolescentes e os jovens representam grupos extremamente vulneráveis para sofrer ou cometer violências, e os centros urbanos são os locais onde se concentram os maiores índices dessas violências ${ }^{6}$.

O Brasil ocupava em 2010 o oitavo lugar dentre os 25 países do mundo com maiores taxas de homicídios de adolescentes. Além disso, tanto as agressões físicas, em ambientes públicos ou em domicílios, quanto os suicídios têm crescido expressivamente entre esse grupo etário ${ }^{5}$.

A violência contra adolescentes é definida de forma abrangente, como todo ato intencional ou omissão capaz de causar danos físico, sexual e/ou psicológico ${ }^{6}$. Implica, de um lado, numa ruptura da expectativa idealizada da proteção que adultos e sociedade em geral deveriam prestar; de outro, numa negação do direito outorgado na contemporaneidade ocidental de serem protegidos como sujeitos e pessoas em condições especiais de crescimento e desenvolvimento ${ }^{2}$.

Os modos de enfrentamento e prevenção às violências contra este segmento ainda são modestos, pouco eficazes, merecendo especial atenção ${ }^{5-8}$. No que concerne às iniciativas da Saúde, o Pacto pela Saúde, de 2006, prevê, por exemplo, o cuidado integral aos adolescentes e a prevenção das violências como uma das ações da Estratégia Saúde da Família (ESF) 9 .

A ESF foi concebida com o propósito de melhorar o estado de saúde da população brasileira, direcionada aos cuidados primários, de forma a responder às demandas, identificando os riscos à vida ${ }^{10}$. É neste contexto abrangente que a ESF está inserida, com responsabilizações ampliadas e cada vez mais abrangentes, visando atender problemas que antes eram menos frequentes ou não incluídos na agenda da saúde ${ }^{11}$.

A ESF é reconhecida em suas premissas como importante estratégia política para o enfrentamento das violências, especialmente no que concerne à sua prevenção ${ }^{12}$. Contudo, apesar do avanço em número de equipes da ESF nas Unidades Básicas de Saúde (UBS) em todo o território nacional, observa-se pouca atuação frente à violência ${ }^{7,13,14}$.

Considerando tais questões, o artigo busca analisar como tem sido a atuação da ESF no enfrentamento das violências envolvendo adolescentes e quais ações tem investido junto a esse segmento na promoção de uma cultura de paz.

\section{Material e método}

O estudo constitui uma revisão bibliográfica integrativa a partir de acervo delimitado pelo conjunto de dissertações e teses da área da saúde. A revisão integrativa é a modalidade de investigação científica que visa reunir a análise de pesquisas relevantes que dão suporte para a tomada de decisão, possibilitando a síntese do estado do conhecimento de um determinado assunto, além de apontar lacunas que precisam ser minimizadas com a realização de novos estudos ${ }^{15}$.

Utilizou-se o Banco de Teses da Biblioteca Virtual do Centro de Aperfeiçoamento Profissional de Ensino Superior - CAPES (http://capesdw. capes.gov.br/capesdw), tendo como critério de busca os descritores: violência, agressão, adolescente, Saúde da Família (SF), Programa Saúde da Família (PSF) e Estratégia Saúde da Família. Considerando que a ESF foi instituída a partir de práticas em SF e do PSF, essas terminologias foram incluídas. O recorte temporal marca o ano de criação do PSF (1994), até o mês de abril (completo) de 2014.

A escolha pela produção da pós-graduação sustenta-se em dois argumentos: 1. a pós-graduação representa o mais alto nível na hierarquia de formação de quadros para pesquisa e assistência, permitindo um retrato da visibilidade do tema nesse lócus; 2. no âmbito da pós-graduação se encontra a maior produção sobre o tema. A busca exploratória na base SciELO, com os mesmos descritores, permitiu um resultado muito mais 
restrito. Considerando o assunto principal "violência”, 1.485 artigos estão disponíveis. Ao refinar a busca com o descritor "saúde da família" (na opção de "todos os índices") são selecionados 16 e desses restam apenas dois artigos quando acrescido o descritor "adolescente" (ambos dos mesmos autores).

A partir do portal da CAPES, obteve-se um total de 134 dissertações e 43 teses. Todos os resumos foram lidos e adotou-se como critério de exclusão estudos que não tratassem a atuação da ESF no enfrentamento das violências envolvendo adolescentes. Também foram excluídos seis estudos com indisponibilidade de acesso ao conteúdo completo, após solicitações às bibliotecas e autores.

$\mathrm{O}$ acervo final constituiu-se de 17 dissertações e duas teses. A partir da leitura dos textos completos, foi feita uma caracterização da produção servindo de cenário inicial de análise.

A interpretação das práticas relatadas e dos sentidos manifestos foi conduzida pela técnica de análise temática ${ }^{16}$ através dos procedimentos: leitura flutuante de cada texto; numeração de cada documento (Fontes de 1 a 19); identificação de eixos temáticos; identificação de representações nucleadoras dos sentidos de cada tema; produção de inferências; e, por fim, diálogo com a literatura.

A análise das ideias centrais permitiu o agrupamento do acervo em três grandes temas: I. Representações das violências envolvendo adolescentes; II. Desafios para tratar a violência na agenda da ESF; III. Propostas apresentadas para atuação da ESF. O primeiro tema trata a ótica dos profissionais entrevistados pelos autores dos estudos, o segundo e o terceiro temas trazem a perspectiva dos autores dos estudos a partir das suas conclusões investigativas. Para tratar o primeiro tema operou-se com a categoria de representações sociais (RS), definidas como o conjunto heterogêneo de ideias e concepções que sustentam "visões de mundo". Sua análise pode ser um caminho para a compreensão de crenças e valores enquanto balizas que influenciam a ação dos sujeitos, ainda que não a determine ${ }^{17}$. Trabalhou-se com um material já interpretado, portanto a RS dos profissionais aqui tratadas são o resultado de sucessivas inferências analíticas dos autores consultados.

\section{Caracterização da produção}

No acervo analisado (Quadro 1) observase que a maior parte da produção foi publicada mais recentemente, sendo mais da metade dos estudos produzida entre 2011 e 2012 ( 11 das 19 publicações). Os dados demonstram o quanto é atual e crescente o interesse pelo estudo do tema.

Nota-se que os municípios de aplicação das pesquisas coincidem com os das instituições de Ensino. A maior parte da produção concentra-se na região Nordeste e Sudeste. Apenas três pesquisas foram realizadas na região Sul, e nenhuma nas regiões Norte e Centro-Oeste. O maior número de estudos em instituições do Nordeste coincide com a região de implantação da ESF no Brasil. Quanto à vinculação à área dos cursos, a maior parte da produção está relacionada à saúde coletiva (13 estudos), outros quatro à enfermagem e dois à psicologia.

Dentre as violências estudadas, 15 estudos tratam da violência familiar. Destes, nove voltaram-se para a RS da violência (quanto às percepções, valores e conhecimentos dos profissionais da ESF), e seis focaram o processo de notificação dessas violências (Quadro 2).

Foi possível observar apenas três pesquisas com enfoques abrangentes, voltadas para a compreensão das RS e os processos de prevenção e cuidados com os adolescentes.

Quando analisado o tipo de metodologia aplicada, 12 estudos foram qualitativos, seis estudos quantitativos e um quanti-qualitativo.

\section{Representações da violência envolvendo adolescentes}

Com base nas RS dos profissionais da ESF, os estudos revelam que algumas vezes as violências parecem personificadas à identidade adolescente. Como se a violência na adolescência representasse em regra um problema social de poucas possibilidades de enfrentamento, demarcando um campo de atuação desafiador para as políticas públicas, consequentemente para a ESF (Fontes $2,4,5,9,8,11,16,17)$.

A violência familiar envolvendo adolescentes foi a mais retratada, objeto de 15 estudos (Fontes 1-7, 9, 10, 12-17). Apenas um estudo (F.1) destaca a sinergia da violência familiar com o poder legitimado socialmente ao homem, que numa relação de desigualdade de gênero acaba por repercutir em abuso, intolerância, desrespeito e submissão à companheira e seus filhos.

A RS da violência familiar é tratada pela ótica da frágil constituição dos laços protetores. Os relatos dos profissionais mencionam que algumas mulheres se acham incapazes de exercer a denúncia contra o seu companheiro, já que o mesmo 
Quadro 1. Caracterização das fontes estudas segundo título da pesquisa, nome dos autores, ano de publicação, instituição de ensino, curso e área de atuação. Brasil, 2006-2012.

\begin{tabular}{|c|c|c|c|c|}
\hline $\begin{array}{l}N^{\circ} \text { da } \\
\text { fonte }\end{array}$ & Título/autor & Ano & Instituição & Curso/área \\
\hline 1 & $\begin{array}{l}\text { "Violência doméstica contra a mulher: } \\
\text { representações de profissionais na Estratégia de } \\
\text { Saúde da Família". Silva Filho CC }\end{array}$ & 2012 & $\begin{array}{l}\text { Universidade Federal } \\
\text { da Bahia - UFBA }\end{array}$ & $\begin{array}{l}\text { Mestrado } \\
\text { Enfermagem }\end{array}$ \\
\hline 2 & $\begin{array}{l}\text { "Notificação de maus tratos em crianças e } \\
\text { adolescentes por profissionais da Estratégia } \\
\text { Saúde da Família”. Moreira GAR }\end{array}$ & 2012 & $\begin{array}{l}\text { Universidade de } \\
\text { Fortaleza - UNIFOR }\end{array}$ & $\begin{array}{l}\text { Mestrado Saúde } \\
\text { Coletiva }\end{array}$ \\
\hline 3 & $\begin{array}{l}\text { "Entre as amarras do medo e o dever } \\
\text { sóciossanitário: notificação da violência contra } \\
\text { crianças e adolescentes sob a perspectiva de rede } \\
\text { na Atenção Primária". Silva JL }\end{array}$ & 2012 & $\begin{array}{l}\text { Universidade Federal } \\
\text { de Pernambuco - } \\
\text { UFPE }\end{array}$ & $\begin{array}{l}\text { Mestrado Saúde } \\
\text { Coletiva }\end{array}$ \\
\hline 4 & $\begin{array}{l}\text { "Notificação de maus-tratos em crianças e } \\
\text { adolescentes em cinco regiões de saúde do } \\
\text { Ceará". Pinto JR }\end{array}$ & 2012 & $\begin{array}{l}\text { Universidade de } \\
\text { Fortaleza - UNIFOR }\end{array}$ & $\begin{array}{l}\text { Mestrado Saúde } \\
\text { Coletiva }\end{array}$ \\
\hline 5 & $\begin{array}{l}\text { "A construção do cuidado: o atendimento às } \\
\text { situações de violência doméstica por euipes de } \\
\text { Saúde da Família". Moreira TNF }\end{array}$ & 2012 & $\begin{array}{l}\text { Universidade de São } \\
\text { Paulo - USP }\end{array}$ & $\begin{array}{l}\text { Mestrado Saúde } \\
\text { Pública }\end{array}$ \\
\hline 6 & $\begin{array}{l}\text { "Impasses no acolhimento de crianças e } \\
\text { adolescentes em situação de violência sexual por } \\
\text { profissionais da Estratégia Saúde da Família". } \\
\text { Trabbold VLM }\end{array}$ & 2012 & $\begin{array}{l}\text { Universidade Federal } \\
\text { de Minas Gerais - } \\
\text { UFMG }\end{array}$ & $\begin{array}{l}\text { Doutorado Ciências } \\
\text { da Saúde }\end{array}$ \\
\hline 7 & $\begin{array}{l}\text { Estratégia de Saúde da Família e o atendimentos } \\
\text { aos adolescentes". Santos BR }\end{array}$ & 2011 & $\begin{array}{l}\text { Universidade Federal } \\
\text { de Santa Maria - } \\
\text { UFSM }\end{array}$ & Mestrado Psicologia \\
\hline 8 & $\begin{array}{l}\text { "Notificação de maus tratos em crianças e } \\
\text { adolescentes em microrregiões de saúde do } \\
\text { Ceará". Silva IZF }\end{array}$ & 2011 & $\begin{array}{l}\text { Universidade de } \\
\text { Fortaleza - UNIFOR }\end{array}$ & $\begin{array}{l}\text { Mestrado Saúde } \\
\text { Coletiva }\end{array}$ \\
\hline 9 & $\begin{array}{l}\text { "Ações de enfermeiros (as) na atenção primária } \\
\text { à saúde de crianças e adolescentes vítimas } \\
\text { de violência doméstica no distrito oeste do } \\
\text { unicípio de Ribeirão Preto-SP”. Leite JT }\end{array}$ & 2011 & $\begin{array}{l}\text { Universidade de São } \\
\text { Paulo - USP }\end{array}$ & $\begin{array}{l}\text { Mestrado } \\
\text { Enfermagem }\end{array}$ \\
\hline 10 & $\begin{array}{l}\text { "Entre o sol e a liberdade impera a violência: } \\
\text { formação de redes para a ação a partir da } \\
\text { estratégia saúde da família". Oliveira KKD }\end{array}$ & 2011 & $\begin{array}{l}\text { Universidade Federal } \\
\text { do Rio Grande do } \\
\text { Norte - UFRN }\end{array}$ & $\begin{array}{l}\text { Mestrado } \\
\text { Enfermagem }\end{array}$ \\
\hline 11 & $\begin{array}{l}\text { "Sensibilização de profissionais de Programa } \\
\text { Saúde da Família (PSF) para notificação de } \\
\text { violência contra criança e adolescente: um } \\
\text { estudo de caso". Bannwart TH }\end{array}$ & 2011 & $\begin{array}{l}\text { Universidade Federal } \\
\text { de Sao Carlos - } \\
\text { UFSCAR }\end{array}$ & Mestrado Psicologia \\
\hline 12 & $\begin{array}{l}\text { "Percepções dos profissionais da Estratégia } \\
\text { Saúde da Família acerca do enfrentamento da } \\
\text { violência entre adolescentes". Ferreira Júnior AR }\end{array}$ & 2010 & $\begin{array}{l}\text { Universidade de } \\
\text { Fortaleza - UNIFOR }\end{array}$ & $\begin{array}{l}\text { Mestrado Saúde } \\
\text { Coletiva }\end{array}$ \\
\hline
\end{tabular}




\begin{tabular}{|c|c|c|c|c|}
\hline \multicolumn{5}{|c|}{ Quadro 1. continuação } \\
\hline $\begin{array}{l}\text { No da } \\
\text { fonte }\end{array}$ & Título/autor & Ano & Instituição & Curso/área \\
\hline 13 & $\begin{array}{l}\text { "Estratégia Saúde da Família e a notificação de } \\
\text { maus tratos contra crianças e adolescentes na } \\
\text { região metropolitana de Fortaleza". Barbosa IL }\end{array}$ & 2010 & $\begin{array}{l}\text { Universidade de } \\
\text { Fortaleza - UNIFOR }\end{array}$ & $\begin{array}{l}\text { Mestrado Saúde } \\
\text { Coletiva }\end{array}$ \\
\hline 14 & $\begin{array}{l}\text { "A percepção de médicos do PSF sobre o } \\
\text { processo de atendimento médico a crianças e } \\
\text { adolescentes vítimas de violência doméstica". } \\
\text { Margarido A }\end{array}$ & 2010 & $\begin{array}{l}\text { Universidade do Vale } \\
\text { do Itajaí - UNIVALI }\end{array}$ & $\begin{array}{l}\text { Mestrado Saúde e } \\
\text { Gestão do trabalho }\end{array}$ \\
\hline 15 & $\begin{array}{l}\text { “Conhecimentos e práticas dos profissionais de } \\
\text { Saúde da Família diante da violência doméstica } \\
\text { contra crianças e adolescentes no município de } \\
\text { Teresópolis-RJ”. Lobato GR }\end{array}$ & 2009 & $\begin{array}{l}\text { Universidade Estácio } \\
\text { de Sá do Rio de } \\
\text { Janeiro }\end{array}$ & $\begin{array}{l}\text { Mestrado Saúde da } \\
\text { Família }\end{array}$ \\
\hline 16 & $\begin{array}{l}\text { "A violência intrafamiliar contra a crianças e o } \\
\text { adolescente na perspectivade profissionais de } \\
\text { saúde". Nunes CB }\end{array}$ & 2007 & $\begin{array}{l}\text { Universidade Federal } \\
\text { de São Paulo - } \\
\text { UNIFESP }\end{array}$ & $\begin{array}{l}\text { Doutorado } \\
\text { Enfermagem }\end{array}$ \\
\hline 17 & $\begin{array}{l}\text { "Violência intrafamiliar contra crianças e } \\
\text { adolescentes na perspectiva dos profissionais } \\
\text { de Saúde da Família: contribuições para uma } \\
\text { política pública de prevenção". Villar EB }\end{array}$ & 2007 & $\begin{array}{l}\text { Universidade Federal } \\
\text { de Uberlândia - UFU }\end{array}$ & $\begin{array}{l}\text { Mestrado Ciências } \\
\text { da Saúde }\end{array}$ \\
\hline 18 & $\begin{array}{l}\text { "Notificação de maus tratos em crianças e } \\
\text { adolescentes por profissionais da equipe Saúde } \\
\text { da Família - Fortaleza (CE)". Luna GLM }\end{array}$ & 2007 & $\begin{array}{l}\text { Universidade de } \\
\text { Fortaleza - UNIFOR }\end{array}$ & $\begin{array}{l}\text { Mestrado Saúde } \\
\text { Coletiva }\end{array}$ \\
\hline 19 & $\begin{array}{l}\text { "A violência familiar contra crianças e } \\
\text { adolescentes e a intervenção das equipes de } \\
\text { Saúde da Família do município de Ponta } \\
\text { Grossa". Sonego C }\end{array}$ & 2006 & $\begin{array}{l}\text { Universidade Estadual } \\
\text { de Ponta Grossa - } \\
\text { UEPG }\end{array}$ & $\begin{array}{l}\text { Mestrado Ciências } \\
\text { Sociais Aplicadas }\end{array}$ \\
\hline
\end{tabular}

Fonte: Capes, abril de 2014.

provê o sustento da família. Enfatiza-se que, nessa dinâmica, a mãe também é vítima de violência (F.10).

A violência sexual foi abordada como uma das mais crescentes manifestações de violência familiar nos territórios. A identificação desses agressores esteve associada à sensação de medo e impotência dos profissionais da ESF, sem que houvesse iniciativa de enfrentamento definida (F.6).

A violência urbana foi a segunda menção dentre as forma de violência envolvendo adolescentes (F. 1,3,4,6,7,9,10,15-17). Todas as 19 pesquisas foram consensuais sobre a percepção dos profissionais da ESF acerca dos riscos à qualidade de vida que as violências urbanas têm trazido aos adolescentes. Alguns estudos reconhecem que os meios de comunicação dão ênfase a esse tema, muitas vezes de forma sensacionalista, reproduzindo percepções de violências que associam linearmente as dinâmicas e os modos de viver das periferias com o tráfico de drogas e as armas (F.3, 6).

Poucas pesquisas propuseram discussões problematizando o envolvimento dos adolescentes com as drogas e a prática de violências. Contudo, a situação foi citada pelos profissionais a partir dos constantes problemas em que estão envolvidos nas comunidades e pela multiplicidade de atos infracionais associados (F.7,10). Enfatizase, ainda, que o uso de drogas entre adolescentes colabora para a valorização do uso da força como 
Quadro 2. Caracterização das fontes estudadas segundo temas, objetivos, método de pesquisa e instrumentos.

\begin{tabular}{|c|c|c|c|}
\hline Temas & Fonte e objetivos & Método & $\begin{array}{c}\text { Instrumento } \\
\text { utilizado para } \\
\text { coleta dos dados }\end{array}$ \\
\hline $\begin{array}{l}\text { Representações sociais, percepções, } \\
\text { conhecimentos e estratégias de } \\
\text { prevenção, proteção e cuidado das } \\
\text { Equipes da ESF frente a situações de } \\
\text { violências. }\end{array}$ & $\begin{array}{l}\text { F.7. Conhecer as demandas } \\
\text { identificadas pelos profissionais da } \\
\text { ESF com foco nos adolescentes. } \\
\text { F.10. Analisar a construção coletiva } \\
\text { de uma rede de proteção à violência. } \\
\text { F.12. Investigar as percepções } \\
\text { dos profissionais da ESFno } \\
\text { enfrentamento da violência entre } \\
\text { adolescentes. }\end{array}$ & Qualitativo & $\begin{array}{l}\text { F.7. entrevista; } \\
\text { F.10. questionário } \\
\text { e entrevista; } \\
\text { F.12. entrevista } \\
\text { e observação } \\
\text { participante; }\end{array}$ \\
\hline \multirow[t]{3}{*}{$\begin{array}{l}\text { Representações Sociais, percepções, } \\
\text { conhecimentos e estratégias de } \\
\text { prevenção, proteção e cuidado das } \\
\text { Equipes da ESF frente a situações de } \\
\text { violência familiar. }\end{array}$} & $\begin{array}{l}\text { F.1. Estudar as representações sociais } \\
\text { dos profissionais da ESF sobre a } \\
\text { violência doméstica contra a mulher } \\
\text { e a assistência prestada à crianças e } \\
\text { adolescentes. } \\
\text { F.5. Compreender as estratégias } \\
\text { de cuidado contra a violência } \\
\text { doméstica com crianças e } \\
\text { adolescentes construídas pela ESF. } \\
\text { F.15. Identificar as percepções } \\
\text { dos profissionais da ESF sobre a } \\
\text { violência doméstica com crianças e } \\
\text { adolescentes. } \\
\text { F.16. Identificar as percepções } \\
\text { sobre a violência intrafamiliar } \\
\text { envolvendo crianças e adolescentes } \\
\text { na perspectiva dos profissiionais de } \\
\text { saúde. }\end{array}$ & Qualitativo & $\begin{array}{l}\text { F.1. teste de } \\
\text { associação livre } \\
\text { de palavras e } \\
\text { entrevista; } \\
\text { F.5. entrevista; } \\
\text { F.15. entrevista } \\
\text { individual; } \\
\text { F.16. entrevista } \\
\text { e observação } \\
\text { participante; }\end{array}$ \\
\hline & $\begin{array}{l}\text { F.17. Avaliar o conhecimento e a } \\
\text { conduta dos profissionais da ESF e } \\
\text { PACS sobre a violência intrafamiliar } \\
\text { contra crianças e adolescentes. }\end{array}$ & Quantitativo & $\begin{array}{l}\text { F.17. questionário, } \\
\text { entrevista; }\end{array}$ \\
\hline & $\begin{array}{l}\text { F.19. Discutir o fenômeno da } \\
\text { violência familiar contra crianças e } \\
\text { adolescentes e analisar a atuação das } \\
\text { equipes da ESF junto aos casos de } \\
\text { ocorrência. }\end{array}$ & $\begin{array}{l}\text { Quanti- } \\
\text { qualitativo }\end{array}$ & $\begin{array}{l}\text { F.19. questionário } \\
\text { e entrevista; }\end{array}$ \\
\hline $\begin{array}{l}\text { Atuação dos enfermeiros da ESF } \\
\text { frente a situações } \\
\text { de violência familiar. }\end{array}$ & $\begin{array}{l}\text { F.9.Conhecer e descrever as ações } \\
\text { de atenção primária prestada por } \\
\text { enfermeiros da ESF às crianças e } \\
\text { adolescentes vítimas de violência } \\
\text { doméstica. }\end{array}$ & Qualitativo & $\begin{array}{l}\text { F.9. entrevistas e } \\
\text { diário de campo; }\end{array}$ \\
\hline $\begin{array}{l}\text { Atuação dos médicos da ESF frente a } \\
\text { situações de violência familiar. }\end{array}$ & $\begin{array}{l}\text { F.14. Investigar a vivência e a } \\
\text { prática diária de médicos da ESF no } \\
\text { atendimento a violência doméstica } \\
\text { contra crianças e adolescentes. }\end{array}$ & Qualitativo & F.14.entrevista; \\
\hline
\end{tabular}




\begin{tabular}{|c|c|c|c|}
\hline \multicolumn{4}{|l|}{ Quadro 2. continuação } \\
\hline Temas & Fonte e objetivos & Método & $\begin{array}{c}\text { Instrumento } \\
\text { utilizado para } \\
\text { coleta dos dados }\end{array}$ \\
\hline $\begin{array}{l}\text { Desenvolvimento e avaliação de } \\
\text { estratégia de capacitação profissional } \\
\text { na temática da violência familiar. }\end{array}$ & $\begin{array}{l}\text { F.11. Sensibilizar os profisisonais do } \\
\text { PSF quanto à prevenção da violência } \\
\text { contra crianças e adolescentes ao } \\
\text { elaborar, propor e avaliar um curso } \\
\text { de capacitação para identificar } \\
\text { e notificar maus-tratos contra } \\
\text { crianças e adolescentes. }\end{array}$ & Quantitativo & F.11.questionário; \\
\hline \multirow[t]{2}{*}{ Notificação de violência familiar. } & $\begin{array}{l}\text { F.3. Identificar os fatores que } \\
\text { influenciam a notificação da } \\
\text { violência contra crianças e } \\
\text { adolescentes sob a perspectiva de } \\
\text { rede pelos profissionais da ESF. }\end{array}$ & $\begin{array}{l}\text { Quanti- } \\
\text { Qualitativo }\end{array}$ & $\begin{array}{l}\text { F.3. questionário } \\
\text { e entrevista; }\end{array}$ \\
\hline & $\begin{array}{l}\text { F.2.Analisar a notificação de maus- } \\
\text { tratos em crianças e adolescentes a } \\
\text { partir da prática da ESF. } \\
\text { F.4. Analisar a notificação de maus- } \\
\text { tratos em crianças e adolescentes } \\
\text { a partir da prática de médicos, } \\
\text { enfermeiros e cirugiões-dentistas } \\
\text { da ESF. } \\
\text { F.8. Identificação das características } \\
\text { dos profissionais da ESF (formação, } \\
\text { tempo de trabalho, variáveis } \\
\text { sociodemográficas) para a } \\
\text { instrumentalização da notificação } \\
\text { de maus-tratos em crianças e } \\
\text { adolescentes. } \\
\text { F.13. compreender a dinâmica } \\
\text { familiar de famílias que possuem } \\
\text { filhos adolescentes envolvidos com } \\
\text { o abuso de drogas, na perspectiva de } \\
\text { suas mães, e compreender a história } \\
\text { de vida familiar } \\
\text { F.18.Analisar o processo de } \\
\text { notificação de maus-tratos em } \\
\text { crianças e adolescentes por médicos, } \\
\text { enfermeiros e cirurgiões dentistas } \\
\text { da ESF. }\end{array}$ & Quantitativo & $\begin{array}{l}\text { F.13. } \\
\text { questionário; } \\
\text { F.18. questionário }\end{array}$ \\
\hline $\begin{array}{l}\text { Identificação e condução profissional } \\
\text { dos casos de violência sexual }\end{array}$ & $\begin{array}{l}\text { F.6. Investigar as práticas discursivas } \\
\text { de diferentes profissionais da ESF } \\
\text { sobre a identificação e condução } \\
\text { dos casos de violência sexual contra } \\
\text { crianças e adolescentes. }\end{array}$ & Qualitativo & F.6. entrevista \\
\hline
\end{tabular}

Fonte: Capes, abril de 2014.

meio de resolução de conflitos, comuns a essa faixa etária (F.7).
O tráfico de drogas e armas chega a ameaçar a rotina de trabalho da ESF, com situações de 
conflitos que envolvem os profissionais, levando à interrupção do atendimento em algumas circunstâncias (F.7).

A violência também é apontada por alguns profissionais como um problema social a ser enfrentado por medidas de repressão, como sendo de competência exclusiva do poder policial (F.4, 8).

Constatou-se nos relatos dos profissionais a ausência de discursos que problematizassem as vulnerabilidades sociais e as motivações dos adolescentes para o envolvimento com ações violentas e as formas de trabalhar tais questões.

\section{Desafios para tratar a violência na agenda da ESF}

A maioria dos estudos reconhece que os profissionais estariam sensibilizados com o crescimento das violências envolvendo adolescentes, porém, destaca-se a ausência de medidas específicas de enfrentamento (F.1,3,4,6,7,9,10,15,16). Todavia, identificou-se resistência de alguns profissionais para acompanhar os casos de violência, sobretudo por não considerarem este tipo de problema pertinente ao setor saúde (F.4,8). A prática contínua de notificação e de acompanhamento dos casos de violências foi mencionada em apenas dois estudos (F.5,17).

A falta de respaldo institucional foi considerada pela análise dos autores como o maior desafio. Os relatos mostram a desarticulação entre instituições e setores que poderiam, junto com a Saúde, atuar como redes de suporte e proteção. Constata-se, ainda, uma incompreensão dos fluxos de encaminhamentos que poderiam fortalecer o acompanhamento dos casos de violências envolvendo adolescentes (F.1-11,13,15,16,17).

Em relação à construção dessas redes de proteção, algumas pesquisas enfatizam que a ESF tem dificuldade no trabalho interdisciplinar e intersetorial $(\mathrm{F} .9,8,11,13,15)$. Contudo, o enfrentamento da violência requer um rompimento do modelo de saúde fragmentado, com vistas à construção de um trabalho que coloque em comunicação os setores, entrelace as possibilidades, fortaleça as potencialidades e dê suporte a variadas iniciativas de enfrentamento e, sobretudo, de prevenção às violências (F.13).

Alguns estudos mostram que profissionais da ESF justificam não atuar em redes devido à sobrecarga de trabalho. Referiram-se à demanda acumulada por serviços assistenciais clínicos que tomava a maior parte do tempo de trabalho. $\mathrm{Na}$ visão dos autores, isto indica a necessidade de uma nova postura de atuação, inclusive de gestão, com administração das demandas e priorização dos agravos (F.2,13,14,16,17).

Outro grande desafio apontado foi a falta de preparo dos profissionais da ESF. Para muitos autores esse é um dos principais empecilhos para o reconhecimento da necessidade de se trabalhar o tema das violências junto aos adolescentes (F.1 $5,9,14,17)$.

Nesse cenário, os relatos dos profissionais afirmam que a maioria dos cursos da saúde não contempla em seus currículos aspectos relacionados às violências, e que, por isso, não se encontram preparados para oferecer ações que tenham impacto efetivo à saúde daqueles envolvidos, seja das vítimas ou dos perpetradores (F.1,2,4,6,7,1114,16).

Segundo boa parte das pesquisas, a maioria dos profissionais nunca recebeu treinamento específico no assunto, não lê, nem discute a temática no ambiente de trabalho (F.2,4,5,12,15). Contudo, mesmo com a realização de algumas oficinas e capacitações, constataram-se dificuldades destes eventos serem incorporados nas agendas dos profissionais da ESF (F.1-11,13,14,15,17).

Quanto ao enfoque dado à notificação, foi quase unânime entre os profissionais da ESF o entendimento sobre a responsabilidade da Saúde na identificação, notificação e acompanhamento dos casos de violências que atingem aos adolescentes (F.1-7, 11, 12, 14, 16). Paradoxalmente, a sub-notificação foi identificada como um grande desafio a ser superado (F.1-4,6-13,16). Alguns profissionais sequer conheciam a Portaria que oficializou a notificação compulsória de violência no Brasil. Outros desconheciam a utilização da ficha de notificação na UBS de referência de atuação da sua ESF (F. 2,9,10,13,15).

A subnotificação foi também relacionada ao desconhecimento de profissionais do que fazer nos casos de violência identificada (F.2,4, 6- 8,10,13). Alguns estudos indicam que entre as equipes houve predomínio para a notificação somente dos casos confirmados, sem a devida responsabilização de acompanhamento das situações $(F .4,13)$. Contudo, para alguns gestores entrevistados, a notificação deveria ser um registro sinalizador para o planejamento e para a gestão em saúde que permitiria a alocação de recursos e a oferta de serviços mais adequados (F.6,11).

O medo foi a justificativa mais citada como causa da subnotificação $(F .4,7,8,11-17)$ pela possibilidade de serem identificados e expostos ao risco de retaliações por parte dos agressores ou por membros da comunidade (F.13,15,16). 
Como visto na primeira seção, há autores que assinalam que o desafio decorre da imagem construída sobre o adolescente, visto como problemático, difícil de lidar, destacando-se como os mais ausentes dentre os demais usuários, o que refletiria, inclusive, no cuidado com a sua saúde (F.11,9,15). Segundo um estudo (F.9), os profissionais da ESF nem mesmo conheciam a existência de um Programa Nacional de Atenção à Saúde do Adolescente.

A questão salarial foi outro ponto citado pelos profissionais da ESF como entrave, pois se sentem mal remunerados, insatisfeitos com as condições de trabalho (infraestrutura, insumos, organização da demanda) - o que desafia a motivação e o compromisso profissional, gerando a procura de outros empregos para complementar a renda (F.16).

Pela escassez de práticas de enfrentamento e prevenção às violências por profissionais da ESF, de relatos de casos e experiências exitosas, opiniões e sugestões, os autores concluem que se faz necessário o fomento a estudos reveladores de como a Estratégia pode melhor atuar (F.2,4,5,12,15).

\section{Propostas apresentadas para a atuação da ESF}

Em geral, os autores consideram que o enfrentamento das violências deveria assumir papel mais relevante na ESF. Enfatizam que certas características, como o campo de atuação dos profissionais da ESF (áreas e micro áreas), com adscrição de clientela, carga horária ampliada, poderiam facilitar a atuação (F.1,3-7,9,10,15,16,17).

A notificação da violência na saúde configurou-se como um dos maiores desafios, (F.1-4,6$13,15,16)$, sendo considerado fundamental que sejam garantidos a implantação da ficha de notificação em todas as UBS da ESF (F.11) e o anonimato da notificação (F.15).

Foi enfaticamente sugerida a realização de capacitação continuada, com suporte técnico que permita a realização das notificações e a ponderação sobre os casos, permitindo identificar fatores de risco e proteção às violências (F.1-7,11,12,15).

Nesse sentido, um estudo pondera que a formação de grupos de promoção de saúde a partir das demandas dos próprios adolescentes, seria atividade mais resolutiva, com maior aceitação e adesão. Abordagens relacionadas às drogas, à sexualidade, às atividades esportivas e à inclusão da atenção psicoterapêutica no acompanhamento de alguns casos são enfoques também sugeridos (F.6).
Outra proposta muito citada pelos autores foi o incremento de ações que promovam maior proximidade da ESF com a comunidade, fortalecendo o vínculo entre usuários e profissionais para alocação de esforços às demandas trazidas pela população. Assim, as violências envolvendo adolescentes, seriam facilmente reconhecidas enquanto um problema prioritário (F.1,2,4,5,7,11,12,16,17).

É também proposto que a partir da identificação das famílias com suspeita ou confirmação de envolvimento em violências com adolescentes, deve haver monitoramento e apoio aos casos com visitas domiciliares periódicas, atendimentos regulares com assistente social, tratamento em saúde em geral (consultas, exames, atendimentos psicológicos e psiquiátricos) e ações de intervenções mais radicais, como acolhimento institucional. Ressaltam, para tanto, a valorização dos conhecimentos dos Agentes Comunitários de Saúde (apontados como essenciais no trabalho da ESF) e, ainda, a importância de aproximações com o Conselho Tutelar, os Centros de Referência Especializada de Assistência Social (CREAS) e escolas (F.2,5,11,12).

A proposta ao trabalho interdisciplinar foi muito sugerida pelos autores (F.1,2,5-7,9,17). Apontam como ganho, o compartilhamento de saberes e práticas, adequação das diretrizes de trabalho e formação das redes de apoio e proteção aos adolescentes. Considera-se que a ESF deve adotar uma postura articuladora com outros serviços e setores na construção de ambientes que garantam a participação popular nas associações comunitárias, nos conselhos locais de saúde, e nas UBS (F.2). Outros estudos $(\mathrm{F} .4,7,11,16)$ propuseram um maior vínculo entre a Saúde e a Educação, a exemplo do Programa Saúde na Escola (PSE). Enfatizam que é preciso assegurar a construção de momentos mais duradouros e que o trabalho em conjunto (PSE e ESF) faça parte da rotina dos profissionais envolvidos (F.4, 7, 11, 16).

Alguns autores entendem ser pré-requisito a ampliação do acesso dos adolescentes à ESF com mecanismos de busca ativa (F.1,15,16). A realização de diagnóstico situacional em saúde foi indicada para a ampliação desse acesso na identificação dos agravos e formas de enfrentamento (F.1-6,8,11,13,15,16). O apoio da gestão da ESF foi considerado essencial para tornar viável a implementação do diagnóstico situacional (F.11,15).

Por fim, aponta-se para a necessidade do incremento de debates e pesquisas sobre o tema, para a construção de estratégias de enfrenta- 
mento das violências envolvendo adolescentes, sintonizadas com a realidade da saúde pública brasileira (F.14).

\section{Discussão}

Percebe-se que o tema da prevenção da violência envolvendo adolescentes no âmbito da ação da ESF só recentemente começa a ser objeto de estudo. Considerando que a ESF foi criada em 1994, passaram-se 12 anos para que o tema ganhasse maior visibilidade.

O conjunto das pesquisas apresenta desigual inserção regional. Mesmo nas regiões onde predominam os estudos, chama a atenção a ausência de pesquisas em estados muito afetados pelas violências envolvendo adolescentes, como é o caso do Espírito Santo, com uma das maiores taxas de violências do país envolvendo esse segmento etário ${ }^{6}$.

O predomínio dos estudos na área de Saúde Coletiva contrasta com a ausência de estudos em outras áreas da saúde, diretamente envolvidas na ESF. A odontologia, por exemplo, inserida na Estratégia desde o ano 2000, não apresentou nenhum estudo acerca do tema.

Ao examinar as percepções dos profissionais da ESF, por um lado, revela-se o conhecimento em torno da indiscutível relevância das violências enquanto um dos mais importantes agravos à saúde dos adolescentes, por outro, sugere uma associação com baixa problematização sobre as imbricadas relações entre as dinâmicas da sociabilidade infantojuvenil e a prática de violências ${ }^{18,19}$.

Observou-se no estudo que a violência familiar, especialmente a agressão física, continua a ser entendida como ação "reservada" à intimidade familiar, sendo difícil de estabelecer, para cada caso, o limite do que é inaceitável ou não, gerando dúvida e medo ao profissional da ESF em notificar e acompanhar os casos, um problema também identificado por outros autores ${ }^{20,21}$.

A violência urbana foi destaque, indicando a reprodução subjacente ao senso comum ${ }^{22}$, da imagem do adolescente como responsável por atos infracionais, envolvido com o tráfico de drogas e armas, impondo à sociedade riscos que interferem na qualidade de vida de todos.

A dificuldade de acesso aos direitos sociais, a pobreza, a baixa qualidade da educação, a falta de oportunidades sociais e a precária efetivação de políticas públicas, colocam os adolescentes em situação de risco e vulnerabilidade, tornando-os indubitavelmente expostos ao envolvimento com práticas criminosas ${ }^{23-25}$. Todavia, observou-se pouca ênfase ao protagonismo juvenil e ao seu empoderamento, tampouco foram mencionadas outras ações apontadas pela OMS e pelo Ministério da Saúde ${ }^{26,27}$ como favoráveis à prevenção das violências, tais como: o trabalho com adolescentes e familiares sobre a construção de projetos de futuro; criação de vínculos de confiança entre os profissionais de saúde e os adolescentes que possibilitem conversas sobre as primeiras relações afetivas e sexuais, envolvimento com álcool, drogas e armas; maior atenção aos adolescentes que sofrem perdas familiares ou desemprego, entre outras ações sugeridas.

Não foram citadas em nenhum estudo a força, o vigor e a criatividade dos adolescentes, características dessa faixa etária que podem propiciar mudanças de posturas, do pensar e do agir com responsabilidade social, o que pode repercutir favoravelmente nas relações comunitárias, promovendo uma cultura de paz $^{28,29}$.

Como consoante ao defendido pela literatura sobre o tema ${ }^{30-32}$, foi consensual entre os autores dos estudos analisados o reconhecimento de que a ESF deveria assumir o enfrentamento e a prevenção das violências envolvendo adolescentes. Todavia, poucas experiências de atuação foram relatadas.

A identificação e a notificação das situações de violências com adolescentes são medidas ainda não incorporadas, o que já deveria fazer parte da rotina de trabalho da ESF como procedimento padrão de ações protetivas ${ }^{20}$. As premissas institucionais da ESF são extremamente claras quanto à necessidade de haver uma postura profissional de proximidade com a comunidade. Permite identificar e atuar nas prioridades que incidem sobre o processo saúde-doença da população adscrita, contrapondo a hegemonia tecnoassistencial na Saúde ${ }^{33}$. Paradoxalmente, foi consenso entre os estudos analisados, a ausência de diagnóstico situacional, não havendo a realização de planejamento e execução de demandas prioritárias, a exemplo das violências envolvendo adolescentes, o que oportunizaria o monitoramento dos casos e o acompanhamento das famílias.

A ESF requer dos seus profissionais uma postura contra-hegemônica, com a incorporação de atitudes que abarquem os conceitos da promoção de saúde. Os profissionais são confrontados a trabalhar em equipe multidisciplinar, compartilhando saberes e práticas de vigilância em saúde, podendo ser necessário empreender parcerias intersetoriais para a formação ou consolidação das redes de apoio e proteção. Com isso, o campo de 
atuação é de fato ampliado, requerendo posturas que antes não eram de responsabilidade do profissional de saúde, o que representa um considerável desafio ${ }^{34-36}$.

Vários estudos sinalizam a necessidade da criação de ambientes comunitários com participação de diversos atores sociais para consolidar redes de proteção e cuidados ao segmento infanto-juvenil ${ }^{37-40}$. Enfatizam que é necessário romper com a lógica do trabalho setorizado e verticalizado; promover o exercício constante de comunicação e troca de informações; capacitar permanentemente todos que participam da rede; incorporar a família nas ações de proteção e de prevenção e promover a participação de amplos setores sociais ${ }^{5,8,9,12,13,23,26,27,29,30,32-39}$.

Essas dificuldades se mostraram muito relevantes na atuação diante das situações de violências envolvendo adolescentes.

Segundo a perspectiva dos profissionais da ESF, pesam como obstáculos à atuação intersetorial a falta de apoio institucional, a pouca compreensão dos fluxos e encaminhamentos diante das situações de violências e a percepção de que há muitos déficits nas redes de proteção e garantia de direitos dos adolescentes. Esses argumentos são também citados na literatura, que conclui haver certa inércia quanto à superação desse desafio para a atuação diante das violências ${ }^{41-42}$.

Estudos demonstram que no âmbito da atenção básica, a saúde dos indivíduos e dos grupos é tomada como objeto de trabalho, mas a família ainda é tratada seguindo-se o modelo da medicalização, sendo a ela dispensada uma atenção fragmentada e focal. Revela-se a necessidade de ampliar a compreensão a partir de um diagnóstico mais amplo de suas necessidades físicas, psicológicas, sociais, econômicas e culturais ${ }^{43}$. Observa-se que diante das suas demandas de saúde, os membros das equipes da ESF têm dificuldades em dar respostas mais abrangentes ${ }^{44-47}$. Tamanha tarefa exige a institucionalização de processos estruturados e sistemáticos de gestão, avaliação e educação em saúde, associada com o compromisso ético, humanístico e social com as famílias cuidadas pelas equipes da $\mathrm{ESF}^{47}$.

A pouca valorização do enfrentamento da violência na formação dos profissionais de saúde ${ }^{8}$ pode ser um cenário explicativo da deficiência de formação sobre o tema (constantemente indicada nos estudos analisados).

Se, por um lado, no conjunto dos estudos analisados foi constante a proposta de realização de capacitações que consigam sensibilizar e melhor apoiar o profissional com a incorporação do tema "violência e saúde" na ESF, por outro, pouco foi problematizado sob quais condições político-pedagógicas tais iniciativas poderiam surtir mais efeito. Questões críticas para a formação do profissional na área da saúde têm sido exaustivamente apontadas, dentre as quais a desarticulação entre a teoria e a prática; a centralização no modelo hospitalocêntrico, com ênfase nas especialidades e em detrimento das práticas de atenção básica/primária à saúde ${ }^{48,49}$. Continuam a ser requeridas novas atitudes perante o conhecimento, capazes de incorporar a interdisciplinaridade e promover o deslocamento para novos espaços de aprendizagem, com destaque para a atenção primária à saúde ${ }^{50}$.

Por fim, confirmando a discussão já travada e a literatura sobre o tema ${ }^{51}$, as iniciativas de prevenção não constituíram destaque, nem relevância na atuação dos profissionais da ESF.

\section{Conclusões}

O cenário que se configura demonstra a necessidade dos profissionais da ESF repensarem suas práticas com vistas à ressignificação da imagem do adolescente, das formas de trabalho de prevenção às violências junto a esse segmento e da promoção de práticas alternativas e criativas que valorizem o protagonismo juvenil, com vistas à promoção de saúde e de uma cultura de paz. A formação dos profissionais sobre o tema; a priorização do problema nas programações de trabalho; a criação de redes de apoio e proteção (incluindo desde a prevenção até o acompanhamento dos casos de violências e das famílias envolvidas) continuam a desafiar gestores e profissionais da ESF e a demandar ações concretas.

\section{Colaboradores}

MF Vieira Netto trabalhou na concepção, pesquisa, metodologia e redação final; SF Deslandes trabalhou na concepção, metodologia e redação final. 


\section{Referências}

1. Organização Mundial da Saúde (OMS). Relatório mundial sobre a violência. Genebra: OMS; 2002.

2. Minayo MCS. A violência social sob a perspectiva da saúde pública. Cad Saude Publica 1994; 10(Supl. 1):S7S18.

3. Souza ER, Ximenes LF, Alves F, Magalhães C, Bilate D, Szuchmacher AM, Malaquias J. Avanços do conhecimento sobre causas externas no Brasil e no Mundo: enfoque quanti e qualitativo. In: Minayo MCS, Souza ER, organizadores. Violência sob o olhar da saúde: a infrapolítica da contemporaneidade brasileira. Rio de Janeiro: Editora Fiocruz; 2003. p. 83-107.

4. Ayres JRCM, França Junior I, Calazans GJ, Saletti Filho HC. O conceito de vulnerabilidade e as práticas de saúde: novas perspectivas e desafios. In: Czeresnia D, Freitas CM. Promoção da saúde: conceitos, reflexões, tendências. Rio de Janeiro: Fiocruz; 2003. p. 117-39.

5. Brasil. Ministério da Saúde (MS). Secretaria de Atenção à Saúde. Impacto da violência na saúde das crianças e adolescentes: prevenção de violências e promoção da cultura de paz: você é a peça principal para enfrentar este problema. Brasília: MS; 2010.

6. Waiselfisz JJ. Mapa da Violência 2014: os jovens do Brasil. Rio de janeiro: Flacso; 2014.

7. Bezerra SC. Estatuto da Criança e do Adolescente: marco da proteção integral. In: Lima CA, organizadores. Violência faz mal à saúde. Brasília. Distrito Federal: Ministério da Saúde; 2004. p. 17-22.

8. Minayo MCS. A inclusão da violência na agenda da saúde: trajetória histórica. Cien Saude Colet 2007; 11(Supl.):1259-1268.

9. Brasil. Ministério da Saúde (MS). Secretaria de Atenção à Saúde. Departamento de Atenção Básica. Política $\mathrm{Na}$ cional de Atenção Básica. Brasília: MS; 2006.

10. Brasil. Ministério da Saúde (MS). Programa de Saúde da Família. Brasília: MS; 1994.

11. Faleiros JJ. Profissionais para reorientar o modelo assistencial: Quantos e quais? Rev Bras Educ Med 2003; 27(1):55-64.

12. Sousa MF, Hamann EM. Programa Saúde da Família no Brasil: uma agenda incompleta. Cien Saude Colet 2009; 14(supl.1):1325-1335.

13. Andrade COM, Barreto ICHC, Bezerra RC. Atenção primária à saúde e estratégia saúde da família. In: Campos GWS, Minayo MCS, Akerman M, Drumond Júnior M, CarcalhoYM, organizadores. Tratado de saúde coletiva. 2a ed. São Paulo: Hucitec; 2009. p. 783-836.

14. Moura EC, Neves ACM, Sá NNB, Silva AS, Santos W. Perfil da situação de saúde do homem no Brasil [relatório]. Rio de Janeiro: Fiocruz; 2012.

15. Benefield LE. Implementing evidence-based practice in home care. Home Health Nurse 2003; 21(12):804-811.

16. Gibbs G. Análise dos dados qualitativos. Porto Alegre: Artmed; 2009. Coleção pesquisa qualitativa.
17. Porto MSG. Crenças, valores e representações sociais da violência. Sociologias 2006; 8(16):250-273.

18. Barbosa PZ, Pegoraro RF. Violência doméstica e psicologia hospitalar: possibilidades de atuação diante da mãe que agride. Saude Soc 2008; 17(3):77-89.

19. Pesce R. Violência familiar e comportamento agressivo e transgressor na infância: uma revisão da literatura. Cien Saude Colet 2009; 14(2):507-518.

20. Zanelatto PF, Medeiros M, Santos WS, Munari, DB. Violência contra crianças e adolescentes: significados e atitudes da estratégia saúde da família. Cien Enfermagem 2012; XVIII(2):41-49.

21. Carmo CJ, Harada MJCS. Physical violence as educational practice. Rev. Latino-Am. Enfermagem 2006; 14(6):849-856.

22. Guimarães SP. Representação social da violência em adolescentes: da norma social ao espaço do sujeito [dissertação]. Goiânia: Universidade Católica de Goiás; 2006.

23. Nunes CB, Sarti CA, Ohara CVS. Concepções de profissionais de saúde sobre a violência intrafamiliar com a criança e o adolescente. Rev Lat Am Enfermagem 2008; 16(1):136-141.

24. Paiva JNM. O Serviço Social no Tribunal de Justiça de Minas Gerais: alguns apontamentos ao adolescente autor de ato infracional. In: Simpósio Mineiro de Assistentes Sociais: nas trilhas dos direitos humanos para combater as desigualdades; 2009; Belo Horizonte.

25. Pierantoni LMM, Cabral IE. Crianças em situação de violência de um ambulatório do Rio de Janeiro: conhecendo seu perfil. Esc Anna Nery Rev Enfermagem 2009; 13(4):699-607.

26. Organização Mundial da Saúde (OMS). Global status report on violence prevention 2014. Genebra: OMS; 2014.

27. Brasil. Ministério da Saúde (MS). Secretaria de Atenção à Saúde. Departamento de Ações Programáticas Estratégicas. Diretrizes Nacionais para a Atenção Integral à Saúde de Adolescentes e Jovens na Promoção, Proteção e Recuperação da Saúde. Brasília: MS; 2010. Série A. Normas e Manuais Técnicos.

28. Vial EA, Junges JR, Olinto MTA, Machado OS, Pattussi MP. Violência urbana e capital social em uma cidade no Sul do Brasil: um estudo quantitativo e qualitativo. Rev Panam Salud Publica 2010; 28(4):289-297.

29. Maldonado MT. Os Construtores da paz: caminhos da prevenção da violência. $3^{a}$ ed. São Paulo: Moderna; 2012.

30. Tanaka OY, Ribeiro EL. Ações de saúde mental na atenção básica: caminho para ampliação da integralidade da atenção. Cien Saude Colet 2009; 14(2):477-486.

31. Dossi AP, Saliba O, Garbin CAS, Garbin AJI. Perfil epidemiológico da violência física intrafamiliar: agressões denunciadas em um município do estado de São Paulo, Brasil, entre 2001 e 2005. Cad Saude Publica 2008; 24(8):1939-1952. 
32. Vieira Netto MF, Emmerich A. Percepção dos coordenadores municipais de saúde bucal sobre a violência estrutural no Estado do Espírito Santo, Brasil. Rev Bras Pesq Saude 2010; 12(2):12-17.

33. Costa GD, Cotta RMM, Ferreira MLSM, Reis JR, Franceschini SCC. Saúde da família: desafios no processo de reorientação do modelo assistencial. Rev Bras Enfermagem 2009; 62(1):113-118.

34. Araujo MBS, Rocha PM. Trabalhando em equipe: um desafio para a consolidação da estratégia saúde da família. Cien Saude Colet 2007; 12(2):455-464.

35. Sousa MF, Hamann EM. Programa Saúde da Família no Brasil: uma agenda incompleta. Cien Saude Colet 2009; 14(supl. 1):1325-1335.

36. Zanelatto PF, Medeiros M, Santos WS, Munari DB. Violência contra crianças e adolescentes: significados e atitudes da estratégia saúde da família. Cien Enfermagem 2012; XVIII(2):41-49.

37. Njaine K, Assis SG, Gomes R, Minayo MCS. Redes de prevenção à violência: da utopia à ação. Cien Saude Colet 2007, 11(Supl.):1313-1322.

38. Deslandes SF, Assis SG, Silva HO. Famílias: parceiras ou usuárias eventuais? Análise de serviços de atenção a famílias com dinâmica de violência doméstica contra crianças e adolescentes. Rio de Janeiro, Brasília: Claves, Unicef; 2004.

39. Gomes R, Minayo MCS, Assis SG, Njaine K, Schenker M. Êxitos na prevenção da violência. São Paulo: Hucitec; 2010.

40. Vial EA, Junges JR, Olinto MTA, Machado OS, Pattussi MP. Violência urbana e capital social em uma cidade no Sul do Brasil: um estudo quantitativo e qualitativo. Rev Panam Salud Publica 2010; 28(4):289-297.

41. Lidchi VG. Fatores de risco e proteção: modelo ecológico do abuso de crianças e adolescentes. In: Williams LCA, Padovani RC, Araújo EAC, Stelko-Prereira AC, Ormenõ GR, Eisenstein E, organizadores. Fortalecendo a rede de proteção da criança e do adolescente. São Carlos: LAPREV; 2009. p. 1-38.

42. Bannwart TH, Brino RF. As dificuldades enfrentadas na identificação e notificação de casos de maus-tratos contra crianças e/ou adolescentes sob a óptica de médicos pediatras. Rev Paul Pediatr 2011; 29(2):138-145.

43. Shimizu HE, Rosales C. As práticas desenvolvidas no Programa Saúde da Família contribuem para transformar o modelo de atenção á saúde? Rev Bras Enferm 2009; 62(3):424-429.

44. Fortuna CM, Mishima SM, Matumoto S, Pereira MJB. Trabalho de equipe no programa de saúde da família: reflexões a partir de conceitos do processo grupal e de grupos operativos. Rev Latino-am enfermagem 2005; 13(2):262-268.
45. Matumoto S, Fortuna CM, Mishima SM, Pereira MJB Domingos NAM. Supervisão de equipes no programa de saúde da família: reflexões acerca do desafio da produção de cuidados. Interface (Botucatu) 2004/2005; 9:9-24.

46. Loch-Neckel G, Seemann G, Eidt HB, Rabuske MM, Crepaldi MA. Desafios para a ação interdisciplinar na atenção básica: implicações relativas á composição das equipes de saúde da família. Cien Saude Colet 2009; 14(Supl.1):1463-1472.

47. Souza MF, Hamann EM. Programa saúde da família no Brasil: uma agenda incompleta? Cien Saude Colet 2009; 14(Supl.1):1325-1335.

48. Batista N, Batista SH, Goldenberg P, Seiffert O, Sonzogno MC. O enfoque problematizador na formação de profissionais de saúde. Rev Saude Publica 2005; 39(2):147-161.

49. Feuerwerker L, Almeida M. Diretrizes curriculares e projetos pedagógicos: é tempo de ação! São Paulo: Rev Abeno 2004; 4(1):14-6.

50. Stella RCR, Abdalla IG, Lampert JB, Perim GL, Aguilar-da-Silva RH, Costa NMSC. Cenários de práticas e a formação médica na assistência em saúde. Rev Bras de Educacão Médica 2009; 33(1Supl.1):63-69.

51. Lobato GR, Moraes CL, Nascimento MC. Desafios da atenção à violência doméstica contra crianças e adolescentes no Programa Saúde da Família em cidade de médio porte do Estado do Rio de Janeiro, Brasil. Cad Saude Publica 2012; 28(9):1749-1758.

Artigo apresentado em 18/03/2015

Aprovado em 03/09/2015

Versão final apresentada em 05/09/2015 
